\title{
Comparison Between Young Males and Females with Acute Myocardial Infarction
}

\author{
Ricardo Augusto Slaibi Conti, Maria Cecília Solimene, Protásio Lemos da Luz, \\ Alexandre Miguel Benjó, Pedro Alves Lemos Neto, José Antônio Franchini Ramires
}

São Paulo, SP - Brazil

\begin{abstract}
Objective - To assess the differences between young males and females after acute myocardial infarction.

Methods - We retrospectively studied 236 patients (54 females and 182 males) after acute myocardial infarction and during hospital stay assessed the following parameters: risk factors; the treatment used; the pattern of coronary artery obstruction; left ventricular ejection fraction; complications; and, using a logistic regression model, the factors related to the occurrence of reinfarction and death.
\end{abstract}

Results - No significant difference was observed between the sexes in risk factors, pattern of coronary artery obstruction, and left ventricular function. The time interval between symptom onset and treatment was longer in females ( $p=0.03)$, who underwent thrombolysis $(p=0.01)$ and angioplasty $(p=0.03)$ less frequently than males did, but not myocardial revascularization. Female sex $(O R=$ 5.98) and diabetes $(O R=14.52)$ were independent factors related to the occurrence of reinfarction and death.

Conclusion - Young males and females after acute myocardial infarction did not differ in coronary risk factors, and clinical and hemodynamic characteristics. Females had their treatment started later, and they underwent chemical thrombolysis and angioplasty less frequently than males did. Female sex and diabetes were related to the occurrence of reinfarction and death.

Keywords: acute myocardial infarction, young, sex, clinical evolution

Instituto do Coração do Hospital das Clínicas - FMUSP

Mailing address: Ricardo Augusto Slaibi Conti - Rua Helio Pellegrino, 300/162 04511-000 - São Paulo, SP, Brazil - E-mail: rconti@uol.com.br
The concept that acute myocardial infarction is not common in young individuals is based on the fact that it occurs in only 4 to $8 \%$ of this population ${ }^{1,2}$. If considered in absolute numbers however, acute myocardial infarction in this age bracket is not infrequent. Considering only the Brazilian hospitals accredited by the Public Health Care System (Sistema Único de Saúde), during the year 2000, 4,549 patients younger than 45 years of age were hospitalized due to acute myocardial infarction ${ }^{3}$.

Acute myocardial infarction has a peculiar presentation in the young population with specific etiopathogenic, anatomic, and prognostic characteristics that differentiate these patients from the elderly ${ }^{1,2,4-6}$. As young patients with acute myocardial infarction get ill during their years of greater productivity, they suffer even more severe psychosocial and economic consequences ${ }^{6,7}$.

Like the age factor, sex seems to influence the clinical presentation of acute myocardial infarction ${ }^{7-11}$. Females with acute myocardial infarction, in addition to being approximately 10 years older than males are, have a higher incidence of systemic arterial hypertension, diabetes mellitus, normal coronary arteries, and clinical signs of heart failure (even though their ejection fraction is not lower than that of males) ${ }^{9-12}$. It has not yet been defined whether the higher mortality in females with acute myocardial infarction occurs because they are affected at a more advanced age, because of the different incidences of several risk factors, or whether an independent association between female sex, morbidity, and mortality after acute myocardial infarction exists ${ }^{8-11}$.

To better understand the characteristics of acute myocardial infarction in young patients, we assessed and compared the differences between the sexes in the incidence of risk factors for coronary artery disease, such as smoking, total hypercholesterolemia, high LDL-cholesterol levels, low HDL-cholesterol levels, hypertriglyceridemia, systemic arterial hypertension, diabetes mellitus, and familial history of early coronary artery disease. We also assessed the electrocardiographic location of acute myocardial infarction, the association between acute myocardial infarction and 
pathological Q waves, the pattern of coronary artery obstruction, left ventricular ejection fraction, in-hospital clinical evolution, treatment, and complications after acute myocardial infarction. And finally we assessed the risk factors for reinfarction and death.

\section{Methods}

We retrospectively studied 236 patients with acute myocardial infarction admitted to the Instituto do Coração of the Hospital das Clínicas of the Medical School of the University of São Paulo from January 1996 to July 1999. This study was approved by the committee on ethics for analysis of research projects of the above-cited hospital.

We selected 25- to 45-year-old patients with the diagnosis of acute myocardial infarction established in the presence of at least 2 of the following criteria: a) clinical: report of pain in the anterior thoracic location, characterized as a pressure, tightness or a burning sensation $>20$ minutes ${ }^{13}$; b) electrocardiographic: elevation of the ST segment $\geq 1 \mathrm{~mm}$, measured 0.02 seconds after the J point or pathological Q wave (duration $\mathrm{m} 0.03$ seconds and amplitude $\mathrm{m} 3 \mathrm{~mm}$ ) in at least 2 contiguous leads of the conventional electrocardiogram, including V7 and V8 ${ }^{14.15}$; c) enzymatic criteria: high levels (above $20 \mathrm{IU}$ ) of the myocardial fraction of creatine phosphokinase (normal value of $10 \mathrm{IU})^{16}$.

Electrocardiograms were performed on hospital admission, after the initial treatment, at the emergency department and repeated daily or in the presence of symptoms or arrhythmias.

Blood samples were collected at the beginning of hospital admission and every 6 hours until normalization of the plasma enzymatic levels.

Patients with at least one of the following conditions were excluded: acute myocardial infarction during or following any surgical procedure; acute myocardial infarction in patients undergoing heart transplantation; patients with congenital cardiac or vascular malformations admitted to the hospital 48 hours after acute myocardial infarction symptom onset.

In this way, 236 patients (182 males and 54 females) with ages ranging from 27 to 45 (mean of $40.8 \pm 3.7$ ) years were selected.

According to the presence of the pathological Q wave in at least 2 contiguous leads, acute myocardial infarction was classified as "Q-wave" and "non-Q-wave" myocardial infarction ${ }^{15}$.

In regard to its electrocardiographic location, acute myocardial infarction was classified as ${ }^{15}$ anterior (septal, anterolateral, high lateral, extensive location) - alteration in 1 or more of the following lead groups: $\mathrm{V}_{1}-\mathrm{V}_{3} ; \mathrm{V}_{4}-\mathrm{V}_{6} ; \mathrm{D}_{1}$ and AVL; inferior (inferior, inferolateral, inferodorsal, laterodorsal, inferolaterodorsal location) - alteration in 1 or more of the following lead groups: $\mathrm{D}_{2}, \mathrm{D}_{3}, \mathrm{AVF} ; \mathrm{D}_{1}, \mathrm{AVL} ; \mathrm{V}_{5}$ and $\mathrm{V}_{6}$; $\mathrm{V}_{7}$ and $\mathrm{V}_{8}$; undetermined - normal electrocardiogram or with left bundle-branch block.

The following risk factors were assessed: a) smoking: active smokers or those who had quit smoking within the 3 years preceding acute myocardial infarction were considered smokers ${ }^{17}$; b) hypercholesterolemia: total cholesterol $>$ $200 \mathrm{mg} / \mathrm{dL}$ (measured during hospitalization) ${ }^{18}$; c) high LDL-cholesterol: LDL-cholesterol $>100 \mathrm{mg} / \mathrm{dL}$ (measured during hospitalization) ${ }^{18}$; d) low HDL-cholesterol: HDL-cholesterol $<35 \mathrm{mg} / \mathrm{dL}$ (measured during hospitalization) ${ }^{18}$; e) hypertriglyceridemia: triglycerides $\mathrm{m} 200 \mathrm{mg} / \mathrm{dL}^{18}$; f) systemic arterial hypertension: we considered as hypertensive those patients taking antihypertensive medication or with a history of systolic blood pressure $\mathrm{m} 140 \mathrm{mmHg}$ or diastolic blood pressure $\mathrm{m} 90 \mathrm{mmHg}$, or both, based on an average of blood pressure measurements on at least 3 different days ${ }^{19}$; g) diabetes mellitus: patients with a history of 2 measurements of fasting plasma glucose $\mathrm{m} 126 \mathrm{mg} / \mathrm{dL}$ on 2 different days or patients with classical symptoms of diabetes associated with glycemia m $200 \mathrm{mg} / \mathrm{dL}^{20}$; h) familial history of early coronary artery disease: report of coronary artery disease in parents or siblings, $<55$ years if males, or $<65$ years if females ${ }^{18}$.

According to the percentage of obstruction of the coronary artery lumen, the obstructive lesions were classified as follows ${ }^{21,22}$ : noncritical - arterial lumen obstruction $<$ $50 \%$; critical - arterial lumen obstruction of $50 \%$ or more; and occlusive - total arterial lumen obstruction, with no flow through the artery.

After calculating the final diastolic (FDA) and final systolic (FSA) areas with planimetry, the ejection fraction was calculated with ventriculography in the right anterior oblique view and the following formula ${ }^{23}$ : $\% \mathrm{EF}=(\mathrm{FDA}-\mathrm{FSA} / \mathrm{FSA}) \times 100^{\mathrm{n}}$.

The following complications occurred early after acute myocardial infarction (in-hospital phase): arrhythmias - complete (right and left) bundle-branch block, (second-degree, high-degree, and total) atrioventricular blocks, atrial tachycardia, atrial fibrillation, atrial flutter, accelerated idioventricular rhythm, ventricular tachycardia, and ventricularfibrillation ${ }^{15,24}$; heart failure-presence of the $3 \mathrm{rd}$ heart sound, clinical signs of pulmonary congestion (dyspnea, orthopnea, crepitant and subcrepitant rales), or arterial hypotension (systolic blood pressure $<90 \mathrm{mmHg}$ ) refractory to volume replacement by intravenous via $^{25}$; mechanical complications ${ }^{25}$ - mitral insufficiency (mitral reflux on left ventriculography), ventricular rupture (confirmed on surgical procedure or on autopsy), interventricular septal defect (presence of systolic flow through the interventricular septum on left ventriculography); postinfarction angina ${ }^{25}$; reinfarction ${ }^{25}$ and death, considered major events during inhospital evolution.

The descriptive analysis of the quantitative variables was performed by calculating the means and standard deviations, while the analysis of the qualitative variables was performed by calculating the absolute and relative frequencies $^{26}$.

The Student $t$ test for independent samples ${ }^{26}$ was used for comparison between the male and female sexes for the quantitative variables with normal distribution and 
sample size $>30$. When the supposed normality of data was rejected or the sample size was $<30$, the comparison of the quantitative variables between the sexes was performed with the nonparametric Mann-Whitney test ${ }^{27}$.

To compare proportions and test sex homogeneity of qualitative variables, the chi-square test was used ${ }^{26}$, except in situations in which the expected frequencies of responses were lower than 5, which required the use of the Fisher exact test ${ }^{26}$.

The variables associated with the occurrence of reinfarction and death were identified with a logistic regression model with a stepwise selection process ${ }^{28}$. For this multivariate analysis, the variables with $p<0.25$ in the univariate analysis were selected.

The statistical significance level of $5 \%(p<0.05)$ and $95 \%$ confidence interval were adopted in the study.

\section{Results}

The mean age was similar for females ( $41 \pm 3.3$ years) and males ( $40.7 \pm 3.8$ years). No statistically significant difference was observed between the sexes in regard to the risk factors assessed (tab. I). For cholesterol fractions, LDLcholesterol values were available in 112 patients $(94$ males and 18 females) and HDL-cholesterol values were available in 119 patients ( 99 males and 20 females). The remaining risk factors were assessed in all patients.

The HDL-cholesterol levels were significantly lower in males $(41.5 \pm 14.4$ in females and $33.2 \pm 10.6$ in males; $p=0.02)$ (tab. II), but when the low HDL variable was tested, the probability was borderline $(\mathrm{p}=0.053)(\mathrm{tab} . \mathrm{I})$.

Infarcts in the inferior wall occurred in $50 \%$ of the females and in $55.3 \%$ of the males ( $\mathrm{p}=0.53$ ) (fig. 1 ), while Qwave infarcts had a similar distribution in both sexes $(81.5 \%$ in females and $82.4 \%$ in males; $\mathrm{p}=0.87$ ).

Coronary angiography was performed in $52(96.3 \%)$ females and 165 (90.7\%) males. Females had twice as many normal coronary angiographies as males $\operatorname{did}(17.3 \%$ and $8.5 \%$, respectively), but the difference was not significant;

\begin{tabular}{|lccc|}
\hline \multicolumn{2}{|c|}{$\begin{array}{c}\text { Table I - Age and risk factors of coronary artery disease in young } \\
\text { individuals with acute myocardial infarction }\end{array}$} \\
\cline { 2 - 3 } Variable & \multicolumn{2}{c|}{ Sex } \\
\cline { 2 - 3 } $\mathrm{P}^{(1)}$ \\
\hline Age (years) & $41 \pm 3.3$ & $40.7 \pm 3.8$ & 0.67 \\
Smoking & $34(63 \%)$ & $136(74.7 \%)$ & 0.09 \\
High total cholesterol & $22(40.7 \%)$ & $100(54.9 \%)$ & 0.07 \\
High LDL-cholesterol & $14(77.8 \%)$ & $83(88.3 \%)$ & 0.26 \\
Low HDL-cholesterol & $7(35 \%)$ & $58(58.6 \%)$ & 0.053 \\
Hypertriglyceridemia. & $12(22.2 \%)$ & $62(34.1 \%)$ & 0.099 \\
Arterial hypertension & $22(40.7 \%)$ & $96(52.7 \%)$ & 0.12 \\
Diabetes mellitus & $5(9.3 \%)$ & $17(9.3 \%)$ & 0.99 \\
Familial history of early & $20(37 \%)$ & $89(48.9 \%)$ & 0.12 \\
coronary artery disease & & & \\
\hline P- Descriptive level of probability with the chi-square test. & \\
\hline
\end{tabular}

\begin{tabular}{|c|c|c|c|}
\hline \multirow[t]{2}{*}{ Lipids (mg/dL) } & \multicolumn{2}{|c|}{ Sex } & \multirow[b]{2}{*}{$P^{(1)}$} \\
\hline & Female & Male & \\
\hline Total cholesterol (2) & $224.3 \pm 69$ & $225.9 \pm 53.2$ & 0.91 \\
\hline LDL-cholesterol (3) & $139.9 \pm 61.7$ & $147 \pm 42.5$ & 0.64 \\
\hline HDL-cholesterol (4) & $41.5 \pm 14.4$ & $33.2 \pm 10.6$ & 0.02 \\
\hline Triglycerides ${ }^{(2)}$ & $194.4 \pm 130.8$ & $234.4 \pm 185.4$ & 0.21 \\
\hline \multicolumn{4}{|c|}{$\begin{array}{l}\text { (1) Descriptive level of probability with the Student } t \text { test; }{ }^{(2)} \text { measured in } \\
236 \text { patients ( } 54 \text { females and } 182 \text { males); }{ }^{(3)} \text { calculated in } 112 \text { patients }(18 \\
\text { females and } 94 \text { males); }{ }^{(4)} \text { measured in } 119 \text { patients ( } 20 \text { females and } 99 \\
\text { males). }\end{array}$} \\
\hline
\end{tabular}

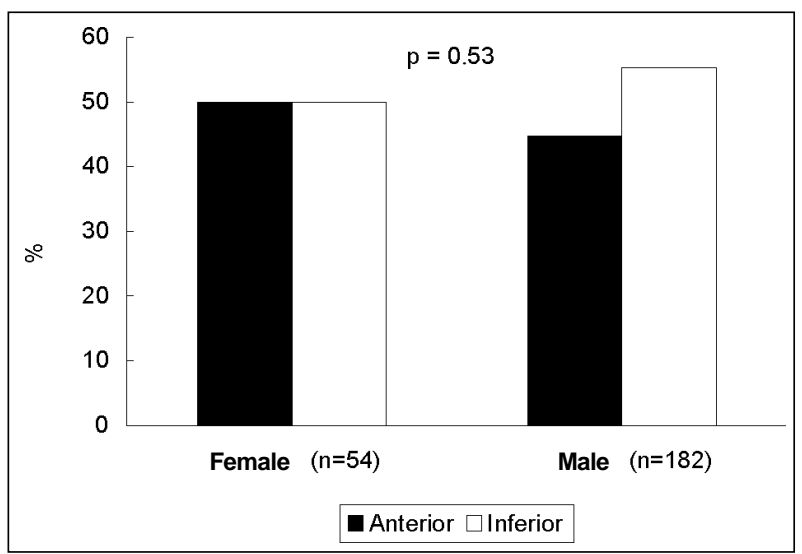

Fig. 1 - Electrocardiographic location of acute myocardial infarction in young patients.

$42 \%$ of the patients, in both groups, had single-vessel disease (fig. 2).

Ventriculography was performed in $150(63.6 \%)$ patients, whose left ventricular ejection fractions were calculated and were similar in males and females; $12.1 \%$ of the females and $6 \%$ of the males had left ventricular ejection fraction $\mathrm{m} 40 \%$ (tab. III).

The time (hours) elapsed between acute myocardial infarction symptom onset and treatment was significantly longer in females than in males (respectively $12.9 \pm 14.6$ and $7.6 \pm 10.3 ; \mathrm{p}=0.03$ ) (fig. 3 ).

The use of thrombolytic agents and angioplasty was significantly lower in the female sex than in the male sex $(\mathrm{p}=0.01 ; \mathrm{p}=0.03$, respectively) (fig. 4). Myocardial revascularization was performed in $16.7 \%$ of the females and in

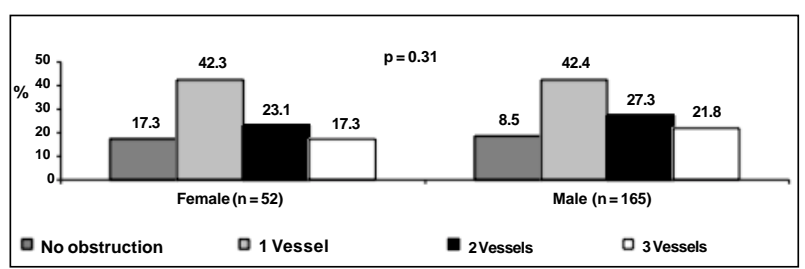

Fig. 2 - Pattern of coronary artery obstruction in young patients with acute myocardial infarction. 


\begin{tabular}{|c|c|c|c|}
\hline \multicolumn{4}{|c|}{$\begin{array}{l}\text { Table III - Left ventricular ejection fraction in young patients with } \\
\text { acute myocardial infarction }\end{array}$} \\
\hline \multirow[t]{2}{*}{ Ejection fraction } & \multicolumn{2}{|c|}{ Sex } & \multirow[b]{2}{*}{$P^{(1)}$} \\
\hline & Female $(\mathrm{n}=33)$ & Male $(\mathrm{n}=117)$ & \\
\hline$>40 \%$ & $29(87.9 \%)$ & $110(94 \%)$ & 0.26 \\
\hline$\leq 40 \%$ & $4(12.1 \%)$ & $7(6 \%)$ & \\
\hline Mean values & $63.4 \pm 19.1$ & $66.4 \pm 14.5$ & 0.43 \\
\hline
\end{tabular}

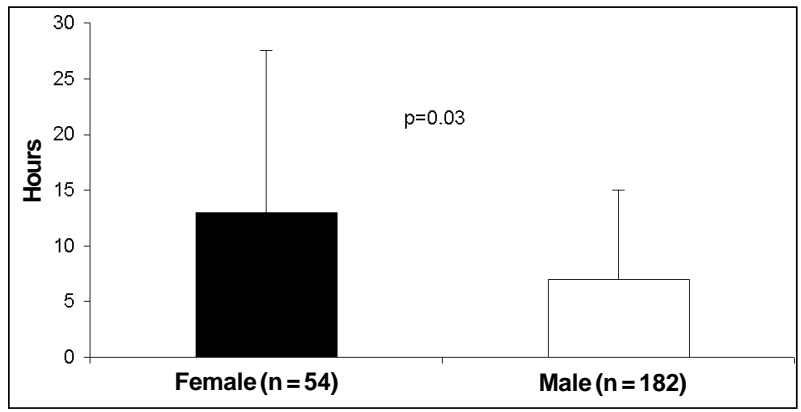

Fig. 3 - Time elapsed between symptom onset and treatment of acute myocardial infarction in young patients.

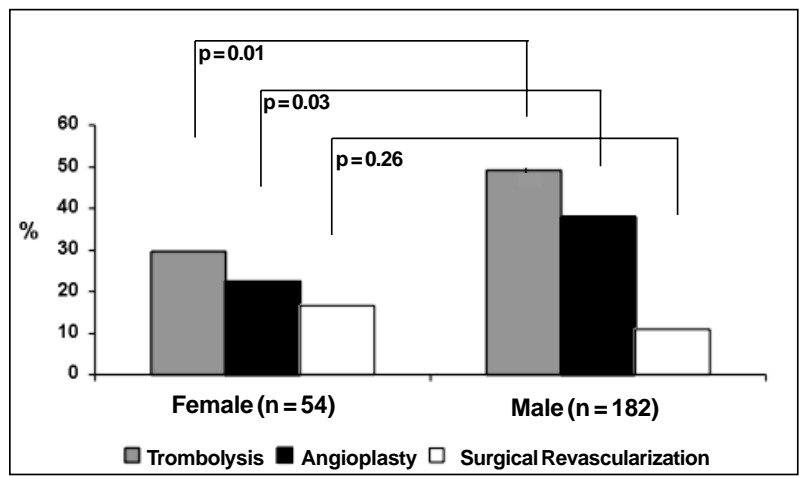

Fig. 4 - Treatment of acute myocardial infarction in young patients.

$11 \%$ of the males, no significant difference being observed $(p=0.26)$.

During hospital stay, complications occurred in $37 \%$ of the females and $30.8 \%$ of the males $(\mathrm{p}=\mathrm{NS})$. The analysis of the complications occurring alone (angina after acute myocardial infarction, heart failure, severe arrhythmias, mechanical complications, reinfarction, and death) did not show any significant difference between the sexes. Although not reaching significant levels $(\mathrm{p}=0.08)$, reinfarction was 3 times more common in females than in males $(11.1 \%$ and $3.8 \%$, respectively) (tab.IV).

Using the logistic regression model, the following parameters were assessed: sex, coronary risk factors, arterial pattern, and left ventricular ejection fraction. Of these variables, those that could foretell reinfarction or death, or both, were $\operatorname{sex}(\mathrm{OR}=5.98)$ and diabetes mellitus $(\mathrm{OR}=14.52)$ (tab. V).

\begin{tabular}{|c|c|c|c|}
\hline \multicolumn{4}{|c|}{$\begin{array}{c}\text { Table IV - In-hospital complications after acute myocardial } \\
\text { infarction in young patients }\end{array}$} \\
\hline & \multicolumn{2}{|c|}{ Sex } & \multirow[t]{2}{*}{$P$} \\
\hline & Female $(\mathrm{n}=54)$ & Male $(\mathrm{n}=182)$ & \\
\hline Postinfarction angina & $9(16.7 \%)$ & $20(11 \%)$ & (1) 0.26 \\
\hline Reinfarction & $6(11.1 \%)$ & $7(3.8 \%)$ & (2) 0.08 \\
\hline Heart failure & $8(14.8 \%)$ & $28(15.4 \%)$ & (1) 0.92 \\
\hline Severe arrhythmias & $9(16.7 \%)$ & $21(11.5 \%)$ & (1) 0.32 \\
\hline Mechanical complications & s 0 & 0 & - \\
\hline Death & $3(5.6 \%)$ & $6(3.3 \%)$ & (2) 0.43 \\
\hline Any complication & $20(37.1 \%)$ & $56(30.8 \%)$ & (1) 0.39 \\
\hline
\end{tabular}

\begin{tabular}{|llllll|}
\hline \multicolumn{5}{|c|}{$\begin{array}{c}\text { Table } \mathbf{V} \text { - Probability of the occurrence of reinfarction and death in } \\
\text { young patients after acute myocardial infarction }\end{array}$} \\
\hline Variable & $\begin{array}{l}\text { Estimated } \\
\text { parameter }\end{array}$ & SD & P & Odds ratio" & IC) A 95\% \\
& -4.171 & 0.698 & 0.0001 & - & - \\
\hline Interception & 1.788 & 0.855 & 0.04 & 5.98 & $1.12 ; 31.97$ \\
$\begin{array}{l}\text { Female sex } \\
\text { Diabetes mellitus }\end{array}$ & 2.675 & 0.917 & 0.003 & 14.52 & $2.41 ; 87.54$ \\
\hline
\end{tabular} $\begin{aligned} & \text { SD - standard deviation; P - descriptive level of probability; CI - confidence } \\
& \text { interval. }\end{aligned}$

\section{Discussion}

In our study, patients up to 45 years of age were selected, according to the criterion in the literature, which considers a patient with acute myocardial infarction young if he or she is $\leq 40$ or 45 years old ${ }^{4-6,29-34}$. The similarity of age between females and males allowed an adequate comparison between the sexes.

In our case series, no significant difference between males and females was observed in the risk factors for coronary artery disease. In acute myocardial infarction, in both sexes, high LDL-cholesterol and smoking were the most prevalent risk factors, while hypertriglyceridemia and diabetes mellitus were the least prevalent. Although HDLcholesterol levels were significantly lower in males (tab. II), when the low HDL variable was tested, no significant difference occurred between males and females (borderline probability; tab. I).

The more elevated estrogen levels in young females and a shorter exposure of the young to the diverse risk factors of coronary artery disease, whose atherogenic effects on the cardiovascular system appear as years go by, may have contributed to the absence of statistically significant differences between the sexes in the risk factors of acute myocardial infarction ${ }^{29-35}$.

We classified as smokers the active smokers and the individuals who had quit smoking in the 3 years preceding infarction, because population studies involving more than 1,000 patients have shown that 3 years after quitting smoking, the risk of acute myocardial infarction or death was similar to that of individuals who had never smoked ${ }^{17}$. The 
fact that no significant difference was found between the sexes in the prevalence of smoking may suggest an increase in the smoking habit among young females. In more advanced age brackets, the prevalence of smoking is still higher among males as compared with that among females with acute myocardial infarction ${ }^{8,36}$.

It has been reported in the literature that the isolated value of LDL-cholesterol plays a less significant role as a cardiovascular risk factor in females as compared with that in males ${ }^{37-39}$. On the other hand, a low HDL-cholesterol level has been considered an important predictor of mortality among females ${ }^{7,35,37-41}$. Currently, a meta-analysis carried out at the National Heart, Lung, and Blood Institute has shown that total hypercholesterolemia and high LDLcholesterol levels correlate with a higher cardiovascular mortality in females younger than 65 years old, but not in the elderly ${ }^{40}$.

The role of triglycerides as an independent risk factor of coronary artery disease is still controversial; some admit their greater importance in females, especially in the elderly ${ }^{42-45}$, mainly due to an increase in thrombotic risk ${ }^{45}$. Our results indicate that, at least in young patients, lipid alterations did not correlate with reinfarction and death. However, the small number of patients in our study does not allow definitive conclusions.

Some authors have reported a low prevalence of systemic arterial hypertension in young patients with acute myocardial infarction ${ }^{6,31}$; our data are not in accordance with these results, because approximately half of our patients, males and females, had a history of systemic arterial hypertension.

One of the factors that may have contributed to the higher prevalence of systemic arterial hypertension in our study was the criterion used for diagnosing hypertension (systolic blood pressure $\geq 140 \mathrm{mmHg}$ or diastolic blood pressure $\mathrm{m} 90 \mathrm{mmHg})^{19,46}$, because in the studies cited, the definition of systemic arterial hypertension requires more elevated blood pressure levels ${ }^{6,31}$. Confirming our observations, Mansur et al ${ }^{47}$ reported that systemic arterial hypertension was the major risk factor of coronary artery disease in 321 females, both in premenopause and postmenopause.

Diabetes mellitus was the least prevalent risk factor in our study, present in $10 \%$ of the patients of both sexes. One possible justification for the lower prevalence of diabetes mellitus in young patients of both sexes after acute myocardial infarction could be the fact that the atherogenic effects of diabetes mellitus on the cardiovascular system appear throughout the years ${ }^{37,48}$. We do not know any study in the literature specifically about the coronary risk caused by diabetes mellitus in young individuals.

Finally, approximately half of the males and females in our case series had a familial history of early coronary artery disease with no statistically significant difference between the sexes. Our results have shown that a familial history of early coronary artery disease is an important cardiovascular risk factor in young patients of both sexes.

In our study, the obstructive lesions in the major coro- nary arteries $\mathrm{m} 50 \%$ were considered critical. Although alterations in coronary flow at rest occur only in the presence of stenoses of the vessel lumen greater than $70 \%{ }^{49}$, that criterion was adopted because the risks of acute myocardial infarction and sudden death do not proportionally relate to the degree of coronary obstruction ${ }^{21,50,51}$, and most infarctions occur after disruption of plaques that do not cause alterations in the coronary flow at rest ${ }^{50,51}$.

Most of our patients of both sexes had single-vessel disease in the coronary arteries. These results are in accordance with those of other reports showing the predominance of critical single-vessel coronary lesions in young patients with acute myocardial infarction ${ }^{4-6}$. Although females had twice as many normal coronary angiographies as compared with males, we found no significant difference in the arterial pattern between the sexes. The higher platelet activity and the more elevated fibrinogen levels in young females ${ }^{52}$ as compared with those in young males could be 1 justification for this difference (although not significant), because acute myocardial infarction with normal coronary arteries may be due to alterations in coagulation in $12.2 \%$ of the cases ${ }^{53}$.

Everything suggests that the endothelial dysfunction resulting from risk factors, such as smoking, dyslipidemia, and arterial hypertension, associated with coronary spasm and thrombosis, plays an important role in the genesis of acute myocardial infarction in younger patients ${ }^{4-6}$. The shorter evolution of atherosclerotic coronary artery disease and the absence of differences between the risk factors of acute myocardial infarction may have been factors that determined the absence of significant differences between the arterial pattern in male and female patients.

In regard to left ventricular ejection fraction, no significant difference was observed between males and females in our sample, and, in regard to the incidence of heart failure after acute myocardial infarction, occurring in approximately $15 \%$ of our patients, no significant difference between the sexes was observed. Several studies involving patients with symptomatic coronary artery disease have shown that the prevalence of heart failure in females is approximately twice that in males, even though left ventricular ejection fraction is equal or even higher in females ${ }^{12,54-57}$. This apparent paradox is attributed to the more frequent presence of diastolic dysfunction in females ${ }^{10,54-57}$.

In our case series, as with those in other centers ${ }^{12,58,59}$, the treatment of acute myocardial infarction in females started significantly later than in males. This may show that the suggestive symptoms of acute myocardial infarction in young females have not yet been properly appreciated either by the patients, who seek medical assistance late, or by the physicians. Even currently, females are more aware of the risks of cancer than of those of cardiovascular diseases ${ }^{60}$.

The fact that the treatment of the females started later may have influenced their therapy, resulting in a higher use of chemical thrombolysis and angioplasty. In addition, the clinical history of acute myocardial infarction of a female 
patient is many times atypical, causing frequent diagnostic errors that interfere with the indication for thrombolysis ${ }^{61-66}$.

Several studies have reported that females undergo surgical myocardial revascularization less frequently than males do ${ }^{67-71}$, a trend that has changed lately ${ }^{72}$. In our study, surgical indication was similar for males and females, maybe because of the absence of statistically significant differences between the sexes in the incidence of triplevessel coronary artery disease and impairment of left ventricular function.

In regard to clinical evolution, no significant difference was observed between the sexes in the occurrence of complications. In the literature, after acute myocardial infarction, females have been reported to have mitral insufficiency, heart failure, ventricular rupture, bradyarrhythmias, and atrial fibrillation more frequently than males do; males have a higher incidence of ventricular tachyarrhythmia (fibrillation and tachycardia) 9,10,56,59. In our study, the absence of differences between the sexes in age, prevalence of systemic arterial hypertension and diabetes mellitus, left ventricular ejection fraction, and coronary artery obstruction pattern may have contributed to the similar incidence of complications.

We diagnosed no mechanical complications after acute myocardial infarction. However, only 3 of the 9 patients who died underwent autopsy, which may have influenced this result.

Reinfarction and death were considered major events. Although significant $(p=0.08)$ levels have not been reached in our study, the 3 times higher reinfarction incidence in females as compared with that in males is noteworthy ( $11.1 \%$ and $3.8 \%$, respectively). Some studies have shown a higher reinfarction rate in females ${ }^{10,59}$, but other reports have not found a significant difference ${ }^{12,55}$. This difference in reinfarction occurrence between males and females could be related to differences in the coagulation and fibrinolytic systems existing between the sexes at any age bracket ${ }^{10,50,51}$.

On the other hand, in our study, a small number of deaths was observed, 3 females and 6 males, during hospital evolution. In terms of percentage, a higher mortality occurred in the female sex than in the male sex, but this difference was not statistically significant; the small number of deaths did not allow conclusions about this result.

Cardiovascular disease is the major cause of death among western females ${ }^{11,73}$, and a number of studies have assessed the relation between sex and mortality after acute myocardial infarction; the results, however, are still controversial ${ }^{9-11,56,66,74,75}$. The greater mortality among females has been related to the fact that they are older and have a higher prevalence of comorbidities, such as systemic arterial hypertension and diabetes mellitus, as compared with males ${ }^{9-11,74,75}$. Some authors, however, consider the female sex as an independent predictor of mortality ${ }^{10}$.

The role played by sex in the mortality rate becomes still less clear when the different age brackets of the patients experiencing acute myocardial infarction are analyzed. Vacarino et $\mathrm{al}^{9}$, in a recent study of 155,565 females and 229,313 males, reported that, after acute myocardial infarction, the younger females have a higher in-hospital mortality compared with that of males of the same age (the younger the female, the higher the mortality). Malacrida et al ${ }^{75}$, however, reviewing the evolution of 36,080 patients of the ISIS-3 study (9,600 females and 26,480 males) disagreed with these results, reporting a lower difference in mortality between males and females with age reduction and only a small sex-independent effect on mortality, which was slightly higher in the female sex $(\mathrm{OR}=1.14)$.

In our study, female sex and diabetes were independent factors related to the occurrence of reinfarction and death.

We believe that several factors may have influenced these results, but the clinical differences between males and females may have been particularly relevant, as may the higher platelet activity and the more elevated fibrinogen levels in females ${ }^{52}$.

On the other hand, diabetes mellitus causes hyperviscosity, endothelial dysfunction, a reduction in fibrinolysis, and an increase in platelet aggregation, in the coagulation factors, in fibrinogen, and in LDL-cholesterol oxidation ${ }^{76-78}$. These factors may contribute, alone or in association, to the occurrence of reinfarction and death.

In conclusion, our results do not show differences between the sexes after acute myocardial infarction in risk factors, coronary artery obstruction pattern, left ventricular ejection fraction, and in-hospital complications in patients aged 45 years or less. On the other hand, the treatment of female patients started later and females underwent chemical or mechanical thrombolysis less frequently than males did. Female sex and diabetes mellitus were identified as independent risk factors for reinfarction and death.

\section{References}

1. Fullhaas JU, Rickenbacher P, Pfisterer M, Ritz R. Long term prognosis of young patients after myocardial infarction in the trombolytic era. Clin Cardiol 1997; 20: 993-8.

2. Zimmerman FH, Cameron A, Fisher L, Grace NG. Myocardial infarction in young adults: angiographic characterization, risk factors and prognosis (coronary artery surgery study registry). J Am Coll Cardiol 1995; 26: 654-61.
3. DATASUS: banco de dados. Disponível em: $<$ http://www.datasus.gov.br/cgi/ tabgci.exe? sih/rnbr.def $>$. Acesso em: 26 jul. 2001.

4. Garoufalis S, Kouvaras G, Perdikouris K, et al. Comparison of angiographic findings, risk factors and long term follow-up between young and old patients with a history of myocardial infarction. Int J Cardiol 1998; 67: 75-80.

5. Chen L, Chester M, Kaski JC. Clinical factors and angiographic features associated with premature coronary artery disease. Chest 1995; 108: 364-9. 
6. Fournier JA, Sánches A, Quero J, Fernandez-Cortacero JAP, Gonzales-Barrero A. Myocardial infarction in men aged 40 years or less: a prospective clinicalangiographic study. Clin Cardiol 1996; 19: 631-6.

7. Da Luz PL, Solimene MC. Peculiaridades da doença arterial coronariana na mulher. Rev Assoc Med Bras 1999; 45: 45-54.

8. Jousilahti P, Vartiainen E, Tuomilehto J, Puska P. Sex, age, cardiovascular risk factors and coronary heart disease. Circulation 1999; 9: 1165-72.

9. Vacarino V, Parsons L, Every NR, Barron HV, Krumholz HM. Sex-based differences in early mortality after myocardial infarction. N Engl J Med 1999; 341: 217-25.

10. Hochman JS, Tamis JE, Thompson TD, et al. Sex, clinical presentation and outcome in patients with acute coronary syndromes. N Engl J Med 1999; 341: 226-31.

11. Wexler LF. Studies of acute coronary syndromes in women-lessons for everyone. N Engl J Med 1999; 341: 275-6.

12. Woodfield SL, Lundergand CF, Reiner JS, et al. Gender and acute myocardial infarction: is there a different response to thrombolysis? J Am Coll Cardiol 1997; 29: 35-42.

13. Alexander RW, Pratt CM, Roberts R. Diagnosis and management of patients with acute myocardial infarction. In: Alexander RW, Schlant RC, Fuster V, eds. Hurst's the Heart, Arteries and Veins. $9^{\text {th }}$ ed. New York: McGraw-Hill, 1998 1345-61.

14. Rude RE, Poole WK, Muller JE, et al. Electrocardiographic and clinical criteria for recognition of acute myocardial infarction based on analysis of 3697 patients. Am J Cardiol 1983; 52: 936-42.

15. Moffa PJ, Sanches PC. Eletrocardiograma normal e patológico. $7^{\mathrm{a}}$ ed. São Paulo: Roca, 2000: 223-530.

16. Turi ZG, Rutherford JD, Roberts R, et al. Eletrocardiographic, enzymatic and scintigraphic criteria of acute myocardial infarction as determined from study of 726 patients (A MILIS Study). Am J Cardiol 1985; 55: 1463-8.

17. Dobson AJ, Alexander HM, Heller RF, Lloyd DM. How soon after quitting smoking does risk of heart attack decline? J Clin Epidemiol 1991; 44: 1247.

18. National Cholesterol Education Program. Second report of the expert panel on detection, evaluation and treatment of high blood cholesterol in adults Circulation 1994; 89: 1336-46.

19. Joint National Committee on Prevention, Detection, Evaluation and Treatment of High Blod Pressure. The sixth report of the joint national committee on prevention, detection, evaluation and treatment of high blood pressure. Arch Intern Med 1997; 157: 2413-44.

20. The Expert Committee on the Diagnosis and Classification of Diabetes Mellitus. Report of the expert committee on the diagnosis and classification of diabetes mellitus. Diabetes Care 1997; 20: 1183-97.

21. Popma JJ, Bittl J. Coronary angiography and intravascular ultrasonography. In: Braunwald E, Zipes DP, Libby P, eds. Heart Disease: A Text Book of Cardiovascular Medicine. $6^{\text {th }}$ ed. Philadelphia: WB Saunders, 2001: 387-421.

22. Varnauskas E. Survival, myocardial infarction, and employment status in a prospective randomized study of coronary bypass surgery. Circulation 1985 72(suppl V): 90-101.

23. Fifer MA, Grossman W. Measurement of ventricular volumes, ejection fraction, mass and wall stress. In: Grossman W, Baim DS, eds. Cardiac Catheterization, Angiography and Intervention. $4^{\text {th }}$ ed. Philadelphia: Lea \& Febiger, 1991: 307.

24. Sgarbossa EB, Pinski SL, Barbagelata A, et al. Eletrocardiographic diagnosis of evolving acute myocardial infarction in the presence of left bundle-branch block. N Engl J Med 1996; 334: 481-7.

25. Julian DG, Braunwald E. Tratamento do Infarto Agudo do Miocárdio. Trad. de Deniza Omena Futuro. Rio de Janeiro: Interlivros, 1996: 448p

26. Rosner B. Fundamentals of Biostatistics. $2^{\text {nd }}$ ed. Boston: PWS Publishers, 1986: 579p.

27. Siegel S. Estatística Não-Paramétrica para as Ciências do Comportamento. New York: MacGraw-Hill, 1975: 350p

28. Hosmer DW, Lemeshow S. Applied Logistic Regression. New York: John Wiley \& Sons, 1989: 307p.

29. Wolfe MW, Vacek JL. Myocardial Infarction in the young. Chest 1988; 94: 926-30.

30. Barbash GI, White HD, Modan M, et al. Acute myocardial infarction in the young - the role of smoking. Eur Heart J 1995; 16: 313-6.

31. Hoit BD, Gilpin EA, Henning H, et al. Myocardial infarction in young patient: an analysis by age subsets. Circulation 1986; 74: 712-21.

32. Uhl GS, Farrel PW. Myocardial infarction in young adults: risk factors and natural history. Am Heart J 1983; 105: 548-53.

33. Chouhan L, Hajar HA, Pomposiello JC. Comparison of thrombolytic therapy for acute myocardial infarction in patients aged $<35$ and $>55$ years. Am J Cardiol 1993; 71: 157-9.

34. Weinberg I, Rotenberg G, Fuchs J. Myocardial infarction in young adults under 30 years: risk factors and clinical course. Clin Cardiol 1987; 10: 9-15.

35. Mosca L, Manson JE, Sutherland SE, Langer RD, Manolio T, Barrett-Connor E
Cardiovascular disease in women: a statement for heathcare professionals from american heart association. Circulation 1997; 96: 2468-82.

36. Rosenberg L, Palmer JR, Shapiro S. Decline in the risk of myocardial infarction among women who stop smoking. N Engl J Med 1990; 322: 213-7.

37. Kannel WB. Metabolic risk factors for coronary heart disease in women: perspective from the Framingham study. Am Heart J 1987; 114: 413-9.

38. Jacobs DR, Mebane IL, Bangdiwala SI, Criqui MH, Tyroler HA. High density lipoprotein cholesterol as a predictor of cardiovascular disease mortality in men and women. The follow-up study of the Lipid Research Clinics Prevalence Study. Am J Epidemiol 1990; 131: 32-4.

39. Moreno GT, Manson JE. Cholesterol and coronary heart disease in women: an overview of primary and secundary prevention. Coron Artery Dis 1993; 4: 580-7.

40. Manolio TA, Pearson TA, Wenger NK, Barrett-Connor E, Payne GH, Harlan WR. Cholesterol and heart disease in older persons and women: review of an NHLBI workshop. Ann Epidemiol 1992; 2: 161-76.

41. Livshits G, Weisbort J, Meshulam N, Brunner D. Multivariate analysis of the 20year follow-up of the Donolo-Tel-Aviv prospective coronary artery disease study and the usefulness of high density lipoprotein cholesterol percentage. Am J Cardiol 1989; 63: 676-81.

42. Gotto AM. Triglyceride. The forgotten risk factor. Circulation 1998; 97: 1027-8.

43. Heyden S, Heiss G, Hames CG, Bartel AG. Fasting triglycerides as predictors of total and CHD mortality in Evans Couty, Georgia. J Chronic Dis 1980; 33 : 275-82.

44. Hokanson JE, Austin MA. Plasma triglyceride level is a risk factor for cardiovascular disease independent of high-density lipoprotein cholesterol level: a metaanalysis of population-based prospective studies. J Cardiovasc Risk 1996; 3 : 213-9.

45. Larosa JC. Triglycerides and coronary risk in women and the elderly. Arch Intern Med 1997; 157: 961-8.

46. III Consenso Brasileiro de Hipertensão Arterial. Campos do Jordão, 1998. Rev Socied Bras de Hipert 1998; 1(supl.): 1-35.

47. Mansur AP, Ramires JAF, Gonçalves EPS, Avakian SD, Caramelli B, Martins JRM. Risk factors, angiographic findings and menopausal status in women with chronic stable coronary heart disease. Cardiovasc Risk Factors 1996; 6: 284-8.

48. Kannel WB. Lipids, diabetes and coronary heart disease: insights from the Framingham Study. Am Heart J 1985; 110 : 1100-7.

49. Ganz P, Ganz W. Coronary blood flow and myocardial ischemia. In: Braunwald E, Zipes DP, Libby P, eds. Heart Disease: A Text Book of Cardiovascular Medicine. $6^{\text {a }}$ ed. Philadelphia: WB Saunders, 2001: 1087-113.

50. Falk E, Shah PK, Fuster V. Coronary plaque disruption. Circulation 1995; 92: 657-71.

51. Kern MJ, Meier B. Evaluation of the culprit plaque and the physiological significance of coronary atherosclerotic narrowings. Circulation 2001; 103 : 3142-9.

52. Berglund U, Wallentin L, Von Schenck H. Platelet function and plasma fibrinogen and their relations to gender, smoking habitis, obesity and betablocker treatment in young survivors of myocardial infarction. Thromb Haemost 1988; 60: 21-4

53. Da Costa A, Isaaz K, Faure E, Mourot S, Cerisier A, Lamaud M. Clinical characteristics, aetiological factors and long-term prognosis of myocardial infarction with an absolutely normal coronary angiogram. Eur Heart J 2001; 22: 1459-65.

54. Mendes LA, Davidoff R, Cupples LA, Ryan TJ, Jacobs AK. Congestive heart failure in patients with coronary artery disease: the gender paradox. Am Heart $\mathrm{J}$ 1997; 134(suppl 2): 207-12.

55. Solimene MC. Aspectos epidemiológicos da isquemia silenciosa em homens e mulheres. Rev Bras Cardiol 2000; 2: 51-6.

56. Marrugat J, Gil M, Sala J. Sex differences in survival rates after acute myocardial infarction. J Cardiovasc Risk 1999; 6: 89-97.

57. Kennedy JW, Kaiser GC, Fisher LD, et al. Clinical and angiographic predictors of operative mortality from the collaborative study in coronary artery surgery (CASS). Circulation 1981; 63: 793-802.

58. Weaver WD, White HD, Wilcox RG, et al. Comparisons of characteristics and outcomes among women and men with acute myocardial infarction treated with thrombolytic therapy. GUSTO-I investigators. JAMA 1996; 275: 777-82.

59. Gottlieb S, HarpazD, Shotan A, et al. Sex differences in management and outcome after acute myocardial infarction in the 1990s. Circulation 2000; 102: 2484-90.

60. Mosca L, Grundy SM, Judelson D, et al. Guide to preventive cardiology for women. Circulation 2000; 102: 2484-90.

61. Yazerbski J, Col N, Pagley P. Gender differences and factors associated with the receipt of thrombolytic therapy in patients with acute myocardial infarction: a community-wide perspective. Am Heart J 1996; 131: 43-50.

62. Ayanian JZ, Epstein AM. Differences in the use of procedures between women and men hospitalized for coronary heart disease. N Engl J Med 1991; 325: 221-5. 
63. Douglas PS, Ginsburg GS. The evaluation of chest pain in women. NEngl J Med 1996; 334: 1311-5.

64. Pope JH, Aufderheider TP, Ruthazer R, et al. Misses diagnosis of acute cardiac isquemia in the emergency department. N Engl J Med 2000; 342: 1207-9.

65. Meta RH, Eagle KA. Missed diagnosis of acute coronary syndromes in the emergency room - continuing challenges. N Engl J Med 2000; 342: 1163-70.

66. Borzak S, Weaver WD. Sex and outcome after myocardial infarction. Circulation, 2000; 102: 2458-9.

67. Funk M, Griffey KA. Relation of gender to the use of cardiac procedures in acute myocardial infarction. Am J Cardiol 1994; 74: 1170-3.

68. Grenberg MA, Mueller HS. Very the excess mortality in women after ptca? Circulation 1993; 87: 1030-1.

69. The Timi Study Group. The Thrombolysis in Myocardial Infarction (TIMI) trial. N Engl J Med 1985; 312: 932-6.

70. Krumholz HM, Douglas PS, Lauer MS, Pasternak RC. Selection of patients for coronary angiography and coronary revascularization early after myocardial infarction: is there evidence for a gender bias? Ann Intern Med 1992; 116: 785-90.

71. Giles WH, Anda RF, Casper ML, Escobedo LG, Taylor HA. Race and sex differences in rates of invasive cardiac procedures in U.S. hospitals. Arch Intern Med 1995; 155: 318-24.
72. Kilaru PK, Kelly RF, Calvin JE, Parrilo JE. Utilization of coronary angiography and revascularization after acute myocardial infarction in men and women risk stratified by the American College of Cardiology/American Heart Association Guidelines. J Am Coll Cardiol 2000; 35: 974-9.

73. Hochman JS, McCabe CH, Stone PH, etal. Outcome and profile of women and men presenting with acute coronary syndromes: a report from TIMI IIIB. J Am Coll Cardiol 1997; 30: 141-8

74. Vacarino V, KrumholzHM, Berkman LF, Horwitz RI. Sex differences in mortality after myocardial infarction: is there evidence for an increased risk for women? Circulation 1995; 91: 61-71.

75. Malacrida R, Genoni M, Maggioni AP, et al. Comparison of the early outcome of acute myocardial infarction in women and men. N Engl J Med 1998; 338: 8-14.

76. Grundy SM, Benjamin IJ, Burke GL, et al. Diabetes and cardiovascular disease. A statement for healthcare professionals from the american heart association. Circulation 1999; 100: 1134-46.

77. Malmberg K, Yusuf S, Gerstein HC, et al. Impact of diabetes on long-term prognosis in patients with unstable angina and non-q-wave myocardial infarction. Circulation 2000; 102: 1014-9.

78. Sherwin RS. Diabetes Mellitus. In: Bennett JC, Plum F, ed. Cecil Textbook of Medicine. $20^{\text {th }}$ ed. Philadelphia: WB Saunders, 1996: 1258-77. 